\title{
INCORPORATING ENVIRONMENTAL OUTCOMES INTO A HEALTH ECONOMIC MODEL
}

\author{
Kevin Marsh \\ Modelling and Simulation, Evidera \\ kevin.marsh@evidera.com \\ Michael Ganz \\ Real-World Evidence, Evidera
}

\author{
Emil Nørtoft \\ Global Health Economics and Outcomes Research, Novo Nordisk \\ Niels Lund \\ Novo Nordisk \\ Joshua Graff-Zivin \\ Department of Economics, University of California San Diego
}

Objectives: Traditional economic evaluations for most health technology assessments (HTAs) have previously not included environmental outcomes. With the growing interest in reducing the environmental impact of human activities, the need to consider how to include environmental outcomes into HTAs has increased. We present a simple method of doing so.

Methods: We adapted an existing clinical-economic model to include environmental outcomes (carbon dioxide $\left[\mathrm{CO}_{2}\right]$ emissions) to predict the consequences of adding insulin to an oral antidiabetic (OAD) regimen for patients with type 2 diabetes mellitus (T2DM) over 30 years, from the United Kingdom payer perspective. Epidemiological, efficacy, healthcare costs, utility, and carbon emissions data were derived from published literature. A scenario analysis was performed to explore the impact of parameter uncertainty.

Results: The addition of insulin to an OAD regimen increases costs by 2,668 British pounds per patient and is associated with 0.36 additional quality-adjusted life-years per patient. The insulin-OAD combination regimen generates more treatment and disease management-related $\mathrm{CO}_{2}$ emissions per patient $(1,686 \mathrm{~kg})$ than the $0 \mathrm{AD}$-only regimen $(310 \mathrm{~kg})$, but generates fewer emissions associated with treating complications $(3,019 \mathrm{~kg}$ versus $3,337 \mathrm{~kg})$. Overall, adding insulin to $0 \mathrm{AD}$ therapy generates an extra $1,057 \mathrm{~kg}$ of $\mathrm{CO}_{2}$ emissions per patient over 30 years.

Conclusions: The model offers a simple approach for incorporating environmental outcomes into health economic analyses, to support a decision-maker's objective of reducing the environmental impact of health care. Further work is required to improve the accuracy of the approach; in particular, the generation of resource-specific environmental impacts.

Keywords: Health technology assessment, Environmental impacts, Economic evaluation

Health technology assessment (HTA) agencies have conventionally required manufacturers to demonstrate the value provided by their products by some form of economic evaluation. Such agencies typically have had a narrow healthcare-focused perspective when considering these evaluations. Against this background, some authors have argued for a broader perspective (1), including calls for HTAs to account for a technology's environmental outcomes in addition to the conventional health outcomes and costs $(2 ; 3)$. However, HTA agencies have shown little interest to date in accounting for environmental issues (3).

The idea that environmental outcomes could be usefully incorporated into HTAs would be consistent with other attempts to recognize and account for the environmental impact of public policies. For example, many governments have committed to environmental objectives, like the Kyoto protocol's targets for reducing greenhouse gas emissions (4). Environmental objectives are also starting to be adopted by healthcare policy mak-

This research was funded by Novo Nordisk A/S. The authors acknowledge the medical writing assistance of Seye Abogunrin (Evidera) and Ike lheanacho (Evidera). ers. For instance, National Health Service (NHS) England in the United Kingdom (UK) has specific targets to decrease carbon dioxide $\left(\mathrm{CO}_{2}\right)$ emissions generated by the healthcare sector, from an estimated 20 million metric tons of carbon dioxide equivalent (MtCO2e) in 2004 to between 11.20 and 12.20 MtCO2e by 2020 and $6.58 \mathrm{MtCO} 2 \mathrm{e}$ by 2050 (5). The Swedish government, too, is considering plans that encourage the use of more environmentally friendly pharmaceuticals by means of an eco-classification system, and by paying a green premium for generic drugs $(6 ; 7)$.

These developments invite questions about whether and how environmental outcomes could also be formally considered in HTAs (8). There are several reasons why we should take this possibility seriously. First, environmental impacts already fall within the scope of the assessment undertaken by some HTA bodies that take a societal perspective, such as TandvårdsOch Läkemedelsförmånsverket. Second, expanding the remit of other HTA bodies to include environmental impacts would be consistent with the opinion of healthcare decision makers who have expressed their interest in maximizing a broader set of social welfare benefits, including environmental outcomes 


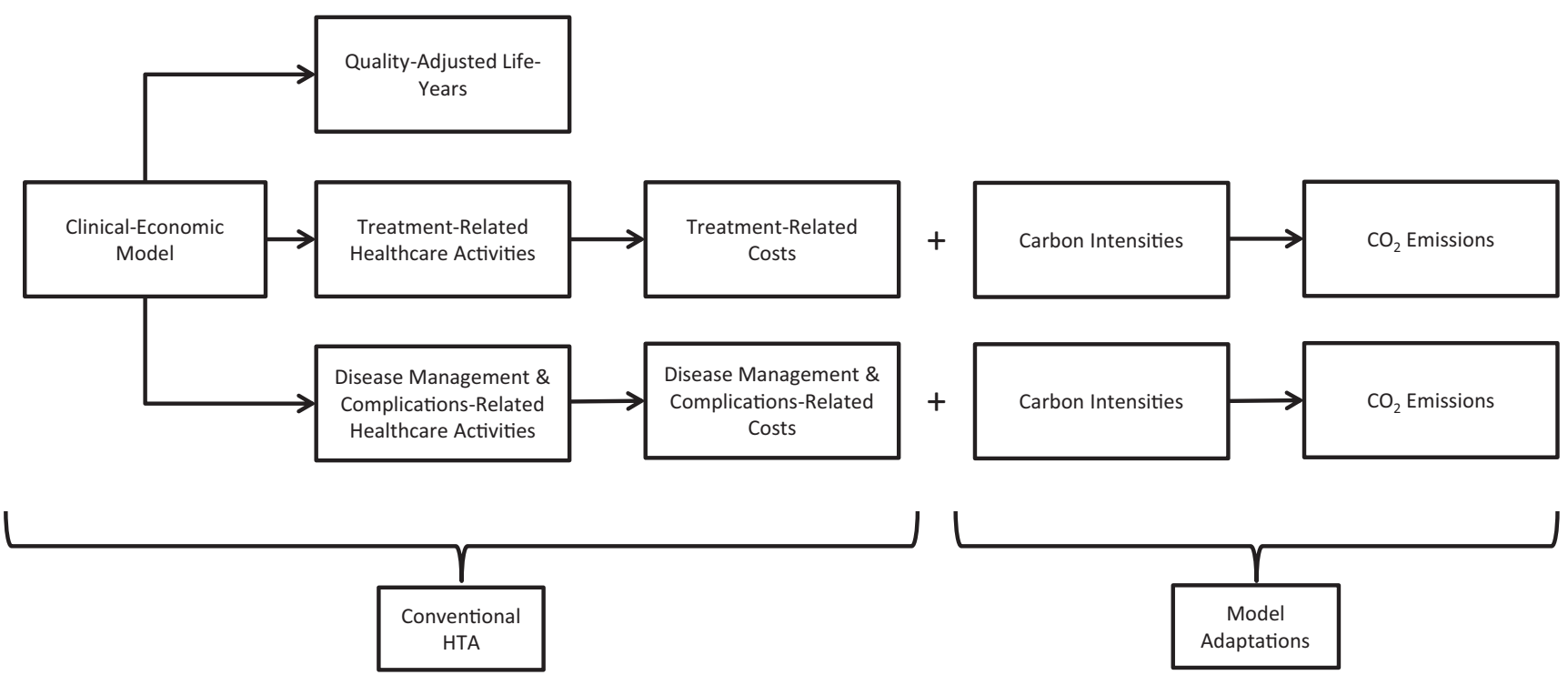

$\mathrm{CO}_{2}$ : carbon dioxide; HTA: health technology assessment.

Figure 1. Model logic for the environmental adaptation to the health economic model

(9). Third, environmental impacts can interfere with a decisionmaker's objective to maximize population health (10-13).

If we accept the policy argument for considering environmental impacts as part of the HTA process, we still face the practical challenge of how to do so. We know of no attempts to estimate the environmental impacts of individual healthcare technologies. However, there have been several attempts to estimate the environmental impacts of health care at a more aggregate level. For example, a healthcare energy impact calculator has been developed to monetize the environmental impact of healthcare energy use in the United States (14), and NHS England has used a quantitative, environmentally extended input-output analysis method to assess its carbon footprint $(15 ; 16)$.

The objective of this study is to describe a model to estimate the environmental impacts generated by an individual health technology, to illustrate how environmental impacts could be incorporated into HTAs, and to describe the challenges this approach is likely to pose.

\section{METHODS}

An existing health economic model was adapted to incorporate environmental impacts, and was applied to assess the health and environmental impacts of insulin treatment for type 2 diabetes mellitus (T2DM). Specifically, direct and indirect costs were combined with carbon intensity data, estimates of the average $\mathrm{CO}_{2}$ emissions emitted per GBP spent delivering health services, to estimate the emissions generated as a result of treatment. Figure 1 presents the model logic.

\section{Interventions}

Our model considers two treatment regimens: an oral antidiabetic (OAD) medication, and the addition of basal insulin therapy to this OAD regimen. Adding insulin to an OAD regimen is consistent with the National Institute of Health and Care Excellence (NICE) guidelines for patients who do not reach clinical targets when treated with an OAD alone (17). Based on 2014 prescription data, we assume that patients add either modern basal insulin ( 80 percent) or human basal insulin (20 percent) (18).

\section{Health Economic Model}

The IMS CORE diabetes model, a validated and wellrecognized patient-simulation model $(19 ; 20)$. was used to assess the impact of the treatments on healthcare costs and health-related quality of life (HRQL) over a 30-year time horizon. Both costs and HRQL were discounted at an annual rate of 3.5 percent, according to the NICE reference case (21). Baseline characteristics of the patients simulated in the model, such as age, sex, duration of diabetes, body mass index, ethnicity, and glycated hemoglobin (HbAlc) levels, were based on the cohort included in a European trial (22). Other patient characteristics that were unavailable from the European trial (including T2DM complications, lipid profile, and blood pressure data), were assumed to be similar to those of patients in the LEAD 1860 study (23).

The treatment outcome was estimated as improvement in $\mathrm{HbA1c}$ level. This information was extracted from a randomized controlled trial of European patients (22), which suggested that HbA1c levels fell from 9.10 percent following treatment 
Table 1. Carbon Footprints, Costs and Carbon Intensities for Specific Treatments ${ }^{a}$

\begin{tabular}{llccc}
\hline Complication & Treatment & $\begin{array}{c}\text { Per capita carbon footprint } \\
(\mathrm{kg} \mathrm{CO2e})\end{array}$ & Per capita cost (GBP) & $\begin{array}{c}\text { Calculated carbon intensity } \\
\text { (kgCO2e/GBP) }\end{array}$ \\
\hline Cataract & Surgery in one eye & $181.80[24]$ & $1,740[29]$ & 0.104 \\
Renal failure & Dialysis (annual) & $10,613.95[25]$ & $26,519[29]$ & 0.400 \\
\hline
\end{tabular}

${ }^{a}$ See Appendix for details.

GBP, British pound.

with OAD to 7.94 percent with the addition of insulin. Treatment costs were computed from UK prescription data (18) and end-of-trial doses (22); the OAD-only regimen costs 50.51 British pounds (GBP)/year, and the OAD-insulin regimen costs 417.22 GBP/year.

\section{Environmental Inputs}

A treatment has both direct and indirect impacts on the environment. Direct effects are generated as a consequence of the raw materials consumed, as well as waste and emissions generated during the manufacturing, distribution, and use of the treatment. Indirect effects are generated as a result of a treatment's health outcomes, which will impact a patient's need for other treatments and services, each of which generates environmental impacts through its manufacture, distribution, and use. Both types of environmental impact are considered by the model.

The environmental impact of treatments is estimated using data on the environmental impact of delivering health care. We identified three sources of healthcare-related $\mathrm{CO}_{2}$ emissions. The first, which we used in our base-case analyses, provided the carbon-intensity of health care in England that was calculated from $\mathrm{CO}_{2}$ emissions and budget data provided by UK NHS. Specifically, the following methods were used to estimate $\mathrm{CO}_{2}$ impacts of treatment: (i) Direct $\mathrm{CO}_{2}$ impact of treatments: we assume that the $\mathrm{CO}_{2}$ intensity of treatment equals the average annual $\mathrm{CO}_{2}$ intensity of pharmaceutical products purchased by the NHS of $0.34 \mathrm{kgCO} 2 \mathrm{e} / \mathrm{GBP}$ (16) and (ii) the indirect $\mathrm{CO}_{2}$ impact of treatment: the indirect costs of treatments, due to general disease management and complications, estimated by the IMS CORE model are converted into $\mathrm{CO}_{2}$ emissions using the NHS estimate of the $\mathrm{CO}_{2}$ intensity of $0.23 \mathrm{kgCO} 2 \mathrm{e} / \mathrm{GBP}(16)$.

The other two sources were used in a scenario sensitivity analysis. These sources estimated the $\mathrm{CO}_{2}$ intensity of cataract surgery (24) and renal services (25) from estimates of their total $\mathrm{CO}_{2}$ footprint and costs derived from the literature (see Table 1 and Supplementary Appendix 1). In the scenario analysis, these $\mathrm{CO}_{2}$ intensity estimates were used to estimate the $\mathrm{CO}_{2}$ impact of T2DM-related eye and renal complications.
As $\mathrm{CO}_{2}$ intensity estimates are applied to discounted costs, the model implicitly discounts emissions at the same rate as health care resource use, 3.5 percent.

\section{Illustration: The Calculation of Treatment-Related Carbon Emission}

The carbon intensity estimates for pharmaceutical treatments were taken from the NHS Sustainable Development Unit (16), who estimated this by dividing the total $\mathrm{CO}_{2}$ impact of the pharmaceuticals used by the NHS in England $(4,380 \mathrm{~m}$ $\mathrm{kgCO} 2 \mathrm{e}$ ) by the amount spent on these pharmaceuticals by the NHS (GBP 12,900 m). This $\mathrm{CO}_{2}$ intensity estimate was applied to direct cost of pharmaceutical treatments in the model to estimate the $\mathrm{CO}_{2}$ emissions generated by use of the treatment. For instance, if the cost of OAD per patient was GBP 100, then OAD would be associated with $\mathrm{CO}_{2}$ emissions of $34 \mathrm{kgCO} 2 \mathrm{e}$ $(\mathrm{GBP} 100 \times 0.34 \mathrm{kgCO} 2 \mathrm{e} / \mathrm{GBP})$.

\section{Model Outputs}

The following conventional health economic outcomes were generated by the model: (i) costs of treating and managing T2DM; (ii) incidence and costs of treating each of the T2DMspecific complications; and (iii) estimates of quality-adjusted life-years (QALYs) lived by the patients. These were used to estimate the incremental cost-utility ratio (incremental costs divided by incremental QALYs gained). This model also estimates total and incremental $\mathrm{CO}_{2}$ emissions and the $\mathrm{CO}_{2}$ emissions by type of service.

\section{RESULTS}

Adding insulin to the OAD regimen increased direct treatment costs by 4,032 GBP and reduced the cost of disease management and complications by 1,384 GBP, for an overall total increase of 2,668 GBP per person (see Table 2). The improvement in Hb1Ac with the addition of insulin also resulted in almost 0.36 additional QALYs per patient. Therefore, each additional QALY comes at a cost of 7,432 GBP.

The healthcare resources associated with the insulin-OAD regimen generated $4,704 \mathrm{~kg}$ of $\mathrm{CO}_{2}$ emissions per person, whereas the OAD-only regimen generated $3,647 \mathrm{~kg}$ of $\mathrm{CO}_{2}$ emissions per person. The treatment of T2DM with the 
Table 2. Model Results (per Patient) at 30 Years ${ }^{a}$

\begin{tabular}{|c|c|c|c|c|}
\hline Model outcomes & Insulin-OAD & OAD & Difference & Source \\
\hline Direct medical costs, discounted GBP & & & & Original economic model \\
\hline Regimen-related & 4,563 & 531 & 4,032 & \\
\hline T2DM management & 584 & 564 & 20 & \\
\hline Complications & 13,125 & 14,509 & $-1,384$ & \\
\hline Direct medical costs, discounted GBP (total) & 18,272 & 15,604 & 2,668 & \\
\hline Quality-adjusted life-years, discounted (total) & 7.20 & 6.84 & 0.36 & \\
\hline Carbon emissions & & & & Model adaptation \\
\hline Regimen-related, $\mathrm{kgCO} e$ & 1551.42 & $180.54 \mathrm{~kg}$ & $1,370.88 \mathrm{~kg}$ & \\
\hline T2DM management, $\mathrm{kgCO} 2 \mathrm{e}$ & 134.32 & $129.72 \mathrm{~kg}$ & $4.60 \mathrm{~kg}$ & \\
\hline Complications, kgCO2e & $3,018.75$ & $3,337.07$ & -318.32 & \\
\hline CVD & 1336.76 & 1531.34 & -194.58 & \\
\hline Renal & 137.56 & 214.82 & -83.26 & \\
\hline Ulcer/amputation/neuropathy & 1326.41 & 1463.72 & -137.31 & \\
\hline Eye & 96.60 & 126.27 & -29.67 & \\
\hline Hypoglycemia & 127.42 & 0.92 & 126.50 & \\
\hline Keto/lactic acidosis & 0.00 & 0.00 & 0.00 & \\
\hline Anti-depression treatment & 0.00 & 0.00 & 0.00 & \\
\hline Carbon emissions, kgCO2e (Total) & $4,704.49$ & $3,647.33$ & $1,057.16$ & \\
\hline
\end{tabular}

insulin-OAD regimen (including disease management) generated direct environmental impacts of $1,686 \mathrm{~kg}$ of $\mathrm{CO}_{2}$ emissions per person compared with $310 \mathrm{~kg}$ of $\mathrm{CO}_{2}$ emissions per person following treatment with the OAD-only regimen (see Table 2). However, this was partly offset by fewer $\mathrm{CO}_{2}$ emissions as a result of fewer complications with the insulin-OAD regimen $(3,019 \mathrm{~kg}$ compared with $3,337 \mathrm{~kg}$ with the OAD-only regimen).

These results were not sensitive to the sources of $\mathrm{CO}_{2}$ intensity data used. The scenario analysis found a minimal impact on the amount of $\mathrm{CO}_{2}$ emissions generated by the use of the insulin-OAD regimen $\left(4,749 \mathrm{~kg}\right.$ of $\mathrm{CO}_{2}$ emissions per person) compared with the OAD-only regimen $\left(3,737 \mathrm{~kg}\right.$ of $\mathrm{CO}_{2}$ emissions per person).

\section{DISCUSSION}

We had two objectives. The first was to illustrate how environmental impacts could be incorporated into HTAs. This study reports a simple method for incorporating environmental impacts into a health economic analysis. Specifically, the analysis assesses the impact of treatments for T2DM on healthcare costs, $\mathrm{HRQL}$, and $\mathrm{CO}_{2}$ emissions. The approach adopted was to estimate the cost and HRQL outcomes associated with the treatments using the IMS CORE model and to estimate the $\mathrm{CO}_{2}$ emissions generated by the associated healthcare resources using $\mathrm{CO}_{2}$ intensity estimates. This approach is not specific to the IMS CORE model, which was used because it is a validated health economic model; the same approach could be applied to other health economic models.

Our second objective was to describe the challenges this approach is likely to pose. Three challenges were identified: (i) Data on environmental impact in a form that could be incorporated into the model was only available for $\mathrm{CO}_{2}$ emissions; (ii) $\mathrm{CO}_{2}$ emissions data were not available at a sufficiently disaggregated level to isolate the impact of individual treatments; and (iii) There is little evidence on how decision makers will use data on the environmental impact of treatments.

As far as we know, ours is the first attempt at incorporating environmental impacts into a health economic analysis of a specific technology. Having done so, we have demonstrated that there are data available for estimating the environmental impact of other health technologies. However, those data have several limitations. $\mathrm{CO}_{2}$ intensity data are available only for top-level healthcare resource categories, such as acute and primary care services and pharmaceuticals. Because these categories cannot yet be directly mapped to the relevant diabetes-related complications, we used the general healthcare $\mathrm{CO}_{2}$ intensity data to estimate $\mathrm{CO}_{2}$ emissions. These $\mathrm{CO}_{2}$ intensity data capture only 
a portion of the environmental impacts associated with healthcare resource use (HCRU) and do not reflect the variation in environmental impact of HCRU for different types of complications.

We explored this issue in our scenario analysis, in which we used the $\mathrm{CO}_{2}$ footprint data for renal services and cataract surgery to generate $\mathrm{CO}_{2}$ intensity estimates specific to these services. The scenario analysis suggests that, although use of these service- and complication-specific $\mathrm{CO}_{2}$ intensity values does not have a significant impact on the overall results of the analysis, the environmental impact of a particular healthcare technology, or for a particular disease area, can vary according to the types of resources used. For example, we found that the $\mathrm{CO}_{2}$ intensity of treating renal failure is 74 percent higher than the NHS average $\mathrm{CO}_{2}$ intensity, and the $\mathrm{CO}_{2}$ intensity of cataract surgery is 55 percent lower than the NHS average.

Further work is required to generate better estimates of the $\mathrm{CO}_{2}$ intensity of healthcare resource use that are specific to the treatment pathways for specific complications, and to generate measures of environmental impacts beyond just $\mathrm{CO}_{2}$ emissions. Some of this work is already under way. For example, the NHS carbon hotspots report (16) lists $\mathrm{CO}_{2}$ intensity values for many types of services related to delivering healthcare services (such as pharmaceuticals and medical instruments), as well as a range of more standard spending categories (such as energy consumption, travel, and administrative services). The report uses these data to estimate the carbon intensity of expenditures for several healthcare categories (such as hospital admissions, inpatient bed days, and outpatient visits) for different types/sectors of healthcare services.

Although service-specific $\mathrm{CO}_{2}$ intensity estimates could improve the accuracy of the model, they would be insufficient to produce an accurate estimate of the environmental impact of new technologies for two reasons: (i) either a technology has yet to be adopted, and so its $\mathrm{CO}_{2}$ emissions will not be reflected in $\mathrm{CO}_{2}$ intensity data; or (ii) $\mathrm{CO}_{2}$ intensity data are estimated at too high a level of aggregation to be able to isolate the impact of individual treatments. It will be necessary to use an alternative method to accurately estimate the environmental impact of individual treatments as part of HTA. One option is life cycle assessment (LCA), a bottom-up approach for collecting data on the resources consumed and the emissions and waste generated during each step of the manufacture, distribution, and use of a technology (26). Although this approach is resource-intensive and time consuming, it at least produces a comprehensive and detailed picture of the direct environmental impact of the technology. Thus, we encourage manufacturers to undertake LCA for their products and make the data available so they can be used for HTA purposes.

Another question raised by the approach to including environmental impacts that we have outlined here is how environmental data should be incorporated into healthcare decision making, and thus, how those data should best be presented to decision makers. This study simply presents the impact on $\mathrm{CO}_{2}$ emissions alongside one of the outputs conventionally generated by HTA, the incremental cost-utility ratio. In the example used here, decision makers are able to see that choosing to invest in the new technology reflects an efficient use of resources (being below the cost-effectiveness threshold, and so generating more health than the marginal use of the NHS budget), but it also results in a higher environmental impact.

One option would be to convert environmental impacts into monetary units using estimates, for instance, of the social costs of carbon (SCC), thereby facilitating an "extended" cost-utility analysis (CUA) that incorporates the environmental impact into the cost numerator. However, the SCC is subject to much uncertainty and debate. SCC estimates are influenced by various factors, including the discount rate; the environmental impacts included in the analysis, with some estimates not including nonmarket damages, risk of extreme weather, population growth, future productivity growth, or socially contingent effects; and the weights given to impacts in different geographical regions $(27 ; 28)$. If SCC estimates are to be incorporated into methods to estimate the environmental impact of health technologies, further work is required to determine policy-makers' preferred SCC methods.

Another alternative would be to use multi-criteria decision analysis (MCDA), an approach that is better established in the field of environmental economics than in health care. MCDA is receiving attention in health care for its ability to capture multiple and conflicting criteria, measured in different units, within a single overall estimate of value (3). While MCDA is currently less accepted than CUA by many HTA agencies (3), further work is warranted to test the feasibility of using these approaches to capture the environmental impacts of health technologies, and to assess decision-makers' preferences for different methods.

Yet another option could be to contextualize the emissions by comparing them with those for the overall healthcare system or for some relevant portion, such as all emissions related to diabetes care. This approach, however, is unlikely to be impactful because the emissions due to any one treatment option, even if extended to all eligible patients, will be very small compared with the larger system. Perhaps as more data on the environmental impacts of health technologies become available and are compiled in some systematic way, as cost-utility data are in various league tables (e.g., the Tufts Medical Center CEA Registry), decision makers will become able to evaluate the tradeoffs between better health outcomes and environmental impacts associated with new treatments.

Given the large monetary costs and known environmental impacts associated with health care and the clearly stated goals of many nations, further research should determine how policy makers would consider environmental impacts when making decisions, and then determine the best way to present the environmental data to support such decision making. 


\section{CONCLUSIONS}

This study presents a simple, feasible option for incorporating environmental impacts into health economic analysis, and thus offers the opportunity to support decisionmakers' evaluation of the environmental impact of health technologies alongside standard HTA criteria. However, further work is required to increase the amount of data available on the environmental impact of health care, and to understand how best this data should be used to support decision makers.

\section{POLICY STATEMENT}

Health technology assessment agencies routinely assess pharmaceutical or health technologies using standard economic evaluation methods. These evaluations have not included environmental criteria to date. The article discusses how environmental impacts can be incorporated into economic evaluations, and suggests a simple and intuitively appealing approach to doing so.

\section{SUPPLEMENTARY MATERIAL}

Supplementary Appendix 1:

https://doi.org/10.1017/S0266462316000581

\section{CONFLICTS OF INTEREST}

Kevin Marsh and Michael Ganz are employees of Evidera which received consulting fees to conduct the research from Novo Nordisk. Emil Nørtoft and Niels Lund are both full-time employees of Novo Nordisk and Niels Lund owns shares at Novo Nordisk. Joshua Graff-Zivin declares no conflict of interest. Novo Nordisk did not have any influence on the interpretation of the data, as well as on the final conclusions drawn. The authors report no other conflicts of interest in this work.

\section{REFERENCES}

1. Devlin NJ, Sussex J. Incorporating multiple criteria in HTA: Methods and processes. London: Office of Health Economics; 2011.

2. Douma KF, Karsenberg K, Hummel MJ, Bueno-de-Mesquita JM, van Harten WH. Methodology of constructive technology assessment in health care. Int J Technol Assess Health Care. 2007;23:162-168.

3. Marsh K, Ganz M, Hssu J, et al. Health technology assessment and environmental costs: Time for health care to catch up? Value Health. 2014;17:A586.

4. United Nations Framework Convention on Climate Change. Kyoto Protocol. 1997 [cited 2015 February 24]; http://unfecc.int/kyoto_protocol/ items/2830.php (accessed February 24, 2015).

5. NHS Sustainable Development Unit. Saving carbon, improving health. Update - NHS Carbon Reduction Strategy. Cambridge: Sustainable Development Unit.

6. Swedish Medical Products Agency. National drug strategy - Action plan. Uppsala, Sweden: Swedish Medical Products Agency; 2011.
7. Socialdepartementet. Utreda om miljöaspekter bör beaktas vid subvention av läkemedel. 2012; http://www.lakemedelsverket.se/ overgripande/Om-Lakemedelsverket/NLS-holder/Minska-lakemedelspaverkan-pa-miljon-lokalt-och-globalt/Utreda-om-miljoaspekterbor-beaktas-vid-subvention-av-lakemedel/ (accessed June 2, 2014).

8. Marsh K, Ganz M, Hssu J, et al. Expanding health technology assessments to include effects on the environment. Value Health. 2016;19: 249-254.

9. Tanios N, Wagner M, Tony M, et al. Which criteria are considered in healthcare decisions? Insights from an international survey of policy and clinical decision makers. Int J Technol Assess Health Care. 2013;29:456465.

10. IPCC. Human health: Impacts, adaptation, and co-benefits. In: Climate Chate 2014: Impacts, adaptation, and vulnerability. Geneva: Intergovernmental Panel on Climate Change; 2014.

11. Costello A, Abbas M, Allen A, et al. Managing the health effects of climate change. Lancet. 2009;373:1693-1733.

12. World Health Organization. Climate change and health. 2013 [cited 2015 May]; http://www.who.int/mediacentre/factsheets/fs266/en/ (accessed May 20, 2015).

13. Briggs D. Environmental pollution and the global burden of disease. $\mathrm{Br}$ Med Bull. 2003;68:1-24.

14. Practice Greenhealth. Healthcare energy impacts calculator. Reston, VA: Practice Greenhealth; 2008.

15. Larsen HN, Solli C, Pettersena J. Supply chain management-How can we reduce our energy/climate footprint? Energy Procedia. 2012;20:354363.

16. NHS Sustainable Development Unit. Goods and services carbon hotspots: NHS England breakdown of goods and services carbon footprint by organisation type (Full Report). UK: NHS Shared Business Services; 2012.

17. National Institute for Health and Care Excellence. Type 2 diabetes: The management of Type 2 diabetes. NICE clinical guideline 87. 2009; Modified 2014. London: National Institute for Health and Care Excellence; 2014.

18. Health \& Social Care Information Centre. Prescription cost analysis, England - 2014 [NS]. 2015 [cited 2015 April]; http://www.hscic.gov.uk/ article/2021/Website-Search?productid $=17711 \&$ q $=$ prescription + cost + analysis\&sort $=$ Relevance \&size $=10 \&$ page $=1 \&$ area $=$ both\#top $($ accessed April 29, 2015).

19. Palmer AJ, Roze S, Valentine WJ, et al. The CORE Diabetes Model: Projecting long-term clinical outcomes, costs and cost-effectiveness of interventions in diabetes mellitus (types 1 and 2) to support clinical and reimbursement decision-making. Curr Med Res Opin. 2004;20(Suppl 1):S5-S26.

20. McEwan P, Foos V, Palmer JL, et al. Validation of the IMS CORE Diabetes Model. Value Health. 2014;17:714-724.

21. NICE. Process and methods guides: Guide to the methods of technology appraisal 2013, National Institute for Health and Care Excellence, Editor. London, UK: National Institute for Health and Care Excellence; 2013.

22. Fritsche A, Schweitzer MA, Haring HU. Glimepiride combined with morning insulin glargine, bedtime neutral protamine hagedorn insulin, or bedtime insulin glargine in patients with type 2 diabetes. A randomized, controlled trial. Ann Intern Med. 2003;138: 952-959.

23. Pratley RE, Nauck M, Bailey T, et al. Liraglutide versus sitagliptin for patients with type 2 diabetes who did not have adequate glycaemic control with metformin: A 26-week, randomised, parallel-group, open-label trial. Lancet. 2010;375:1447-1456.

24. Morris DS, Wright T, Somner JE, Connor A. The carbon footprint of cataract surgery. Eye (Lond). 2013;27:495-501. 
Marsh et al.

25. Connor A, Lillywhite R, Cooke MW. The carbon footprint of a renal service in the United Kingdom. QJM. 2010;103:965-975.

26. Environmental Protection Agency. Life cycle assessment: Principles and practice by scientific applications international corporation. Cincinnati, OH: Environmental Protection Agency; 2006. http://nepis.epa. gov/Exe/ZyPDF.cgi/P1000L86.PDF?Dockey=P1000L86.PDF (accessed April 29, 2015).

27. Watkiss P. The Social Costs of Carbon (SCC) review - Methodological approaches for using SCC estimates in policy assessment: Final re- port. Department for Environment, Editor. Norwich, UK: Office of Public Sector Information; 2005.

28. Nordhaus WD. Estimates of the social cost of carbon: Background and results from the RICE-2011 model. Cambridge, MA: National Bureau of Economic Research; 2011.

29. Davies MJ, Chubb BD, Smith IC, Valentine WJ . Cost-utility analysis of liraglutide compared with sulphonylurea or sitagliptin, all as addon to metformin monotherapy in Type 2 diabetes mellitus. Diabet Med. 2012;29:313-320. 